\title{
Tranilast enhances the effect of anticancer agents in osteosarcoma
}

\author{
TAKAYUKI NAKASHIMA ${ }^{1}$, SATOSHI NAGANO $^{1}$, TAKAO SETOGUCHI ${ }^{2}$, HIROMI SASAKI $^{1}$, \\ YOSHINOBU SAITOH $^{1}$, SHINGO MAEDA ${ }^{2}$, SETSURO KOMIYA ${ }^{1}$ and NOBORU TANIGUCHI ${ }^{1}$ \\ Departments of ${ }^{1}$ Orthopaedic Surgery and ${ }^{2}$ Medical Joint Materials, \\ Graduate School of Medical and Dental Sciences, Kagoshima University, Kagoshima 890-8520, Japan
}

Received September 12, 2018; Accepted April 19, 2019

DOI: $10.3892 /$ or.2019.7150

\begin{abstract}
Tranilast[N-(3',4'-dimethoxycinnamoyl)-anthranilic acid], initially developed as an antiallergic drug, also exhibits a growth inhibitory effect on various types of cancer. Osteosarcoma is treated mainly with high-dose methotrexate, doxorubicin, cisplatin and ifosfamide; however, 20-30\% of patients cannot be cured of metastatic disease. We investigated whether tranilast enhances the anticancer effects of chemotherapeutic drugs and analyzed its mechanism of action in osteosarcomas. Tranilast inhibited proliferation of HOS, 143B, U2OS and MG-63 osteosarcoma cells in a dose-dependent manner, as well as enhancing the effects of cisplatin and doxorubicin. The average combination index at effect levels for tranilast in combination with cisplatin was 0.57 in HOS, 0.4 in 143B, 0.39 in U2OS and 0.51 in MG- 63 cells. Tranilast and cisplatin synergistically inhibited the viability of osteosarcoma cells. In flow cytometric analysis, although tranilast alone did not induce significant apoptosis, the combination of tranilast and cisplatin induced early and late apoptotic cell death. Expression of cleaved caspase-3, cleaved poly(ADP-ribose) polymerase and $\mathrm{p}-\mathrm{H} 2 \mathrm{AX}$ was enhanced by tranilast in combination with cisplatin. Tranilast alone increased expression of p21 and Bim protein in a dose-dependent manner. Cell cycle analysis using flow cytometry demonstrated that the combination of tranilast and cisplatin increased the number of cells in the G2/M phase. Compared with cisplatin alone, the combination increased levels of phospho-cyclin-dependent kinase 1 (Y15). In the 143B xenograft model, tumor growth was significantly inhibited by combined tranilast and cisplatin compared with the controls, whereas cisplatin alone did not significantly inhibit tumor growth. In conclusion, tranilast has a cytostatic effect on osteosarcoma cells and enhances the effect
\end{abstract}

Correspondence to: Dr Satoshi Nagano, Department of Orthopaedic Surgery, Graduate School of Medical and Dental Sciences, Kagoshima University, 8-35-1 Sakuragaoka, Kagoshima 890-8520, Japan

E-mail: naga@m2.kufm.kagoshima-u.ac.jp

Key words: tranilast, osteosarcoma, cisplatin, G2/M arrest, apoptosis of anticancer drugs, especially cisplatin. Enhanced sensitivity to cisplatin was mediated by increased apoptosis through G2/M arrest. Since tranilast has been clinically approved and has few adverse effects, clinical trials of osteosarcoma chemotherapy in combination with tranilast are expected.

\section{Introduction}

Tranilast [N-(3',4'-dimethoxycinnamoyl)-anthranilic acid] was developed as an antiallergic drug for the treatment of inflammatory diseases, including bronchial asthma, atypical dermatitis, allergic conjunctivitis, keloids and hypertrophic scars (1). It has also been shown that tranilast is effective in a wide range of conditions such as vascular injury (2), osteoporosis (3), diabetes, autoimmune disease, ocular disease and renal fibrosis (1). The largest clinical trial to explore new applications of tranilast was the Prevention of REStenosis with Tranilast and its Outcomes (PRESTO) trial (4), which examined whether tranilast decreased the frequency of angiographic restenosis after percutaneous coronary intervention. Although the PRESTO trial failed to show improvement in the incidence of restenosis, researchers have been investigating the efficacy of tranilast for several other diseases $(3,5,6)$. Tranilast has been shown to have an inhibitory effect on the growth of various types of cancer cells, including breast $(7,8)$, prostate (9), pancreas (10), lung (11) and stomach (12). However, tranilast has not been approved for cancer treatment.

Osteosarcoma is the most common primary malignant bone tumor and is generally treated with preoperative chemotherapy, surgery and postoperative chemotherapy. Although prognosis has improved for patients with localized disease, patients with metastatic disease still have a poor prognosis. The most popular chemotherapeutic drugs, including high-dose methotrexate, doxorubicin, cisplatin and ifosfamide, are used to eradicate micrometastases; however, $20-30 \%$ of patients cannot be cured of metastatic disease, especially in the lungs (13). Although new anticancer agents for soft tissue sarcoma (pazopanib, eribulin and trabectedin) have been approved over the past 10 years, only one drug (mifamurtide) has been approved for osteosarcoma in Europe but not in the USA) in the past 20 years. Therefore, we investigated whether tranilast, which has been widely used clinically without severe adverse effects, enhances the anticancer effect of existing chemotherapeutic drugs. Furthermore, we analyzed the 
mechanism of action of tranilast when it acts synergistically with anticancer drugs.

\section{Materials and methods}

Cell culture. Osteosarcoma cell lines 143B, U2OS and MG-63 were obtained from the American Type Culture Collection (ATCC; Manassas, VA, USA). HOS and normal dermal fibroblast WI-38 cell lines were obtained from RIKEN BioResource Center (Tsukuba, Japan). These cell lines were cultured in Dulbecco's modified Eagle's medium (DMEM; Sigma-Aldrich, Merck KGaA; Darmstadt, Germany) supplemented with $10 \%$ fetal bovine serum (Thermo Fisher Scientific, Inc., Waltham, MA, USA), $100 \mathrm{U} / \mathrm{ml}$ penicillin (Thermo Fisher Scientific, Inc.) and $100 \mu \mathrm{g} / \mathrm{ml}$ streptomycin (Thermo Fisher Scientific, Inc.). Cell lines were maintained for up to 20 passages at $37^{\circ} \mathrm{C}$ in $5 \% \mathrm{CO}_{2}$. Regarding p53 status, HOS, 143B and MG-63 express mutant p53 $(14,15)$, whereas U2OS expresses wild-type p53 (16).

Analysis of cell viability. Cells were treated with tranilast (Tokyo Chemical Industry, Co., Ltd., Tokyo, Japan), doxorubicin (Sigma-Aldrich, Merck KGaA) and cisplatin (Tokyo Chemical Industry). After $48 \mathrm{~h}$ of treatment, cell viability was analyzed using a colorimetric assay for mitochondrial dehydrogenase activity (WST-1; Roche Diagnostics, Basel, Switzerland), as previously described (17).

Cell cycle analysis. Human osteosarcoma cells were cultured with $2 \mu \mathrm{M}$ cisplatin or $100 \mathrm{nM}$ doxorubicin with or without $200 \mu \mathrm{M}$ tranilast. An equivalent volume of vehicle was used as the control. Cell cycle analysis was performed $48 \mathrm{~h}$ after treatment, as previously reported (17). Cells were collected, fixed with $70 \%$ ethanol at $-20^{\circ} \mathrm{C}$, washed with phosphate-buffered saline (PBS), and treated with Guava Cell Cycle reagent (Merck Millipore, Burlington, MA, USA). DNA content was examined using flow cytometry (CytoFLEX; Beckman Coulter, Brea, CA, USA).

Cell apoptosis analysis. Human osteosarcoma cells were cultured for $48 \mathrm{~h}$ with or without $200 \mu \mathrm{M}$ tranilast or $2 \mu \mathrm{M}$ cisplatin, and an equivalent volume of vehicle was used as the control. Cells were treated with the Annexin V-FITC/7-ADD kit (Beckman Coulter), and fluorescence-activated cell sorting was performed on a CytoFLEX flow cytometer (Beckman Coulter).

Western blotting. Western blotting was performed as previously described (18). Cells were lysed using NP40 buffer, which contained $0.5 \%$ NP-40, $10 \mathrm{mM}$ Tris- $\mathrm{HCl}(\mathrm{pH} 7.4)$, $150 \mathrm{mM} \mathrm{NaCl}, 3 \mathrm{mM}$ phenylmethylsulfonyl fluoride (Wako Pure Chemical Industries Co., Ltd., Kanagawa, Japan), $5 \mathrm{mg} / \mathrm{ml}$ aprotinin (Sigma-Aldrich; Merck KGaA), $2 \mathrm{mM}$ sodium orthovanadate (Wako Pure Chemical Industries) and $5 \mathrm{mM}$ EDTA. Lysates were boiled in SDS sample buffer (10 $\mu \mathrm{g}$ of protein loaded per lane), separated using SDS-PAGE (4-15\% gradient gel; cat no. 456-1086; Bio-Rad Laboratories, Hercules, CA, USA) and transferred to polyvinylidene fluoride (PVDF) membranes (Caliper Life Sciences, Inc., Mountain View, CA, USA). Membranes were blocked in
5\% non-fat dry milk in Tris-buffered saline Tween-20 (TBST) and incubated with primary antibodies against cleaved caspase-3 (dilution 1:500; cat. no. 9661; Cell Signaling Technology, Danvers, MA, USA), cleaved poly(ADP-ribose) polymerase (cleaved PARP; dilution 1:500; cat. no. 5625; Cell Signaling Technology), H2A histone family member X (H2AX; dilution 1:1,000; cat. no. 7631; Cell Signaling Technology) phospho-H2AX (p-H2AX; dilution 1:1,000; cat. no. 2577; Cell Signaling Technology), p21 (dilution 1:1,000; cat. no. 2947; Cell Signaling Technology), Bim (dilution 1:1,000; cat. no. 2933; Cell Signaling Technology), ataxia telangiectasia and Rad3-related kinase (ATR; dilution 1:500; cat. no. 13934; Cell Signaling Technology), phospho-ATR (p-ATR; dilution 1:500; cat. no. 58014; Cell Signaling Technology), checkpoint kinase 1 (CHK1; dilution 1:500; cat. no. 2360; Cell Signaling Technology), phospho-CHK 1 (p-CHK1; dilution 1:500; cat. no. 12302; Cell Signaling Technology), cyclin-dependent kinase 1 (CDK1; dilution 1:500; cat. no. 28439; Cell Signaling Technology), phospho-CDK1 at Y15 (p-CDK1 Y15; dilution 1:500; cat. no. 9111; Cell Signaling Technology), p-CDK1 T161 (dilution 1:500; cat. no. 9114; Cell Signaling Technology), Wee1 (dilution 1:500; cat. no. 13084; Cell Signaling Technology), poshpo-Wee1 (p-Wee1; dilution 1:500; cat. no. 4910; Cell Signaling Technology) and tubulin (dilution 1:1,000; cat. no. 66031-1-IG; Proteintech Group, Inc., Rosemont, IL, USA) diluted in TBST overnight at $4^{\circ} \mathrm{C}$. Blots were washed using TBST and incubated with horseradish-peroxidase-conjugated secondary antibodies (anti-rabbit; dilution 1:5,000; cat. no. 7074; Cell Signaling Technology, or anti-mouse; dilution 1:5,000; cat. no. 7076; Cell Signaling Technology) in TBST for 1 or $2 \mathrm{~h}$ at room temperature. Immunocomplexes were visualized using an enhanced chemiluminescence kit (ECL; GE Healthcare, Tokyo, Japan).

Drug combination studies. Synergism after treatment with tranilast and cisplatin was evaluated using CalcuSyn software version 2 (Biosoft, Ferguson, MO, USA), which is based on the median-effect principle originally established by Chou and Talalay (19). From the fraction affected by the dose obtained from cell proliferation assays and the dose of drug, the software draws a dose-effect curve and calculates the median-effect dose $\left(\mathrm{ED}_{50}\right)$. For each combined dose effect, a combination index (CI) was generated. The effects of the combinations were then transformed into and displayed as fraction-affected CI plots. If the data of single-agent and combination use were inputted, the software calculated the $\mathrm{CI}$, which represented the pharmacological interaction of two drugs. A CI value of 1 indicates an additive effect between the two agents, whereas $\mathrm{CI}<1$ or $\mathrm{CI}>1$ indicates synergism or antagonism, respectively.

Animal studies. Experiments with a xenograft mouse model were performed as follows: a total of 24 mice (5-week-old; nude mice; weight, 18-24 g, Nihon SLC, Hamamatsu, Japan) were housed in the animal facility under a 12 -h day/night cycle, temperature of $23 \pm 1^{\circ} \mathrm{C}$, relative humidity of $50 \pm 10 \%$ with ad libitum access to food and water. Suspensions of $1 \times 10^{6} 143 \mathrm{~B}$ cells in $100 \mu \mathrm{l}$ Matrigel (Corning Inc., Corning, NY, USA) were subcutaneously 
inoculated into the flank of mice. Xenograft models were randomly divided into four groups of either treatment with tranilast $400 \mathrm{mg} / \mathrm{kg} / \mathrm{day}$, cisplatin $4 \mathrm{mg} / \mathrm{kg}$ twice weekly, a combination of tranilast and cisplatin, or an equal volume of vehicle as a control. Tumor volume and body weight was measured twice a week. Tumor volume $(\mathrm{V})$ was calculated using the following formula: $\mathrm{V}=\mathrm{LW}^{2} / 2$, where $\mathrm{L}$ and $\mathrm{W}$ indicate the length and width of the tumors, respectively. All animal humanely sacrificed by $\mathrm{CO}_{2}$ inhalation when they met the following humane endpoint criteria: Severe tumor burden (the maximal diameter of tumor exceeded $20 \mathrm{~mm}$ ), weight loss exceeded $10 \%$ of the total weight, prostration and difficulty of breathing. All animal experiments were performed in compliance with the guidelines of the Institute of Laboratory Animal Sciences, Graduate School of Medical and Dental Sciences, Kagoshima University. Every effort was made to minimize both the number of animals used and animal pain.

Statistical analysis. For the in vitro experiments, data are expressed as mean \pm standard deviation $(\mathrm{SD})$ values shown from three independent experiments. Statistical analysis was performed by one-way analysis of variance (ANOVA) followed by Tukey's post hoc test. To analyze the difference between the dose-response curves for tranilast in osteosarcoma and fibroblast, ANCOVA (analysis of covariance) was used. For the in vivo experiment, statistical analysis was performed with a non-parametric multiple comparison test using the Steel-Dwass method. $\mathrm{P}<0.05$ was considered to indicate a statistically significant difference.

\section{Results}

Tranilast inhibits the proliferation of osteosarcoma cells. Osteosarcoma cell lines (HOS, 143B, U2OS and MG-63) and normal fibroblasts (WI-38) were treated with tranilast (50, $100,200,300,400$ and $500 \mu \mathrm{M}$ ) for $48 \mathrm{~h}$ and cell viability was determined. The effect of tranilast was small, although proliferation was inhibited in all four cell lines in a dose-dependent manner (Fig. 1). $\mathrm{IC}_{50}$ values for HOS, 143B, U2OS and MG-63 cells were 130.4, 329.0, 252.4 and $332.6 \mu \mathrm{M}$, respectively. In contrast, the $\mathrm{IC}_{50}$ value for WI-38 was $444.7 \mu \mathrm{M}$. At $200 \mu \mathrm{M}$ of tranilast, the viability of all four osteosarcoma cell lines were significantly reduced compared with that of WI-38 fibroblasts (ANOVA with Tukey's test, vs. HOS, $\mathrm{P}=0.00001$; vs. $143 \mathrm{~B}, \mathrm{P}=0.0008$; vs. $\mathrm{U} 2 \mathrm{OS}, \mathrm{P}=0.001$; vs. $\mathrm{MG}-63, \mathrm{P}=0.02$ ). Therefore, we performed experiments using the combination treatment of tranilast and anticancer drugs at $200 \mu \mathrm{M}$ of tranilast. Analysis of covariance (ANCOVA) of cell viability at $0-500 \mu \mathrm{M}$ demonstrated significant statistical difference between the four osteosarcoma cell lines and normal fibroblast WI-38 (vs. HOS, $\mathrm{P}=0.0007$; vs. 143B, $\mathrm{P}=0.0005$; vs. $\mathrm{U} 2 \mathrm{OS}, \mathrm{P}=0.0001$; vs. MG-63, $\mathrm{P}=0.0003$ ).

Combined treatment with tranilast and anticancer agents, cisplatin and doxorubicin enhances the cytotoxic effect on osteosarcoma cells. To determine whether tranilast enhances the effect of anticancer agents, osteosarcoma cells were treated with combined tranilast and anticancer drugs. Tranilast significantly enhanced the effect of cisplatin on osteosarcoma cell lines in regards to reduced cell viability (Fig. 2A). Tranilast also significantly enhanced the cytotoxic effect of doxorubicin in regards to reduced cell viability (Fig. 2B). However, the enhancement was less than that for cisplatin because the cell lines were relatively sensitive to doxorubicin. Next, we examined whether tranilast and cisplatin inhibited cell proliferation in a synergistic manner. We examined CIs using synergistic characteristics after treatment with tranilast and cisplatin. Dose-effect and fraction-affected CI plots in HOS, 143B, U2OS and MG-63 cells are shown in Fig. 3. Average $\mathrm{CI}$ values at $\mathrm{ED}_{50}, \mathrm{ED}_{75}$ and $\mathrm{ED}_{90}\left(\mathrm{ED}_{50}-\mathrm{ED}_{90} \mathrm{CI}\right)$ for tranilast in combination with cisplatin were 0.57 in HOS, 0.4 in 143B, 0.39 in U2OS and 0.51 in MG-63 cells. The results demonstrated that tranilast and cisplatin synergistically inhibited the viability of the osteosarcoma cell lines.

Tranilast enhances cisplatin-mediated apoptotic cell death in osteosarcoma cells. To analyze the mode of cell death induced by the combined treatment with tranilast and cisplatin in HOS, 143B, U2OS and MG-63 osteosarcoma cells, flow cytometry was performed. Tranilast alone did not induce significant apoptotic death in all cell lines (Fig. 4). Cisplatin induced apparent accumulation of the cells in early and late apoptosis. The combination of tranilast and cisplatin enhanced both early and late apoptotic cell death (Fig. 4A). The increase in apoptotic cell fraction by combined tranilast and cisplatin was statistically significant in all four osteosarcoma cell lines compared with single treatment with tranilast or cisplatin (Fig. 4B). Especially, combined treatment induced a significantly higher percentage of apoptotic cells in HOS ( $\mathrm{P}=0.03), 143 \mathrm{~B}(\mathrm{P}=0.0001), \mathrm{U} 2 \mathrm{OS}$ $(\mathrm{P}=0.02)$ and MG-63 $(\mathrm{P}=0.007)$ than that by cisplatin alone.

Western blotting demonstrated increased cleaved PARP, cleaved caspase-3 and p-H2AX, which are hallmarks of cisplatin-induced apoptotic cell death (Fig. 5A). Expression of cleaved caspase-3, cleaved PARP and p-H2AX was enhanced by combined tranilast and cisplatin (Fig. 5A and B). Expression of p21 was increased in a dose-dependent manner by tranilast (Fig. 5C). Expression of Bim, a proapoptotic protein, was also increased by tranilast treatment (Fig. 5C). Apoptotic protein induction by tranilast and cisplatin, and upregulation of $\mathrm{p} 21$ and Bim protein levels by tranilast were less in the MG-63 osteosarcoma cell line.

Tranilast enhances cisplatin-induced $G 2 / M$ arrest in osteosarcoma cells. We examined the cell cycle population after tranilast and/or cisplatin treatment in osteosarcoma cells. HOS, 143B, U2OS and MG-63 cells were treated with cisplatin $(2 \mu \mathrm{M})$, tranilast $(200 \mu \mathrm{M})$, and the combination of both drugs, and were analyzed using flow cytometry at $48 \mathrm{~h}$ after treatment. Tranilast induced a small increase in the G1 population of U2OS cells (p53 wild-type) but not of HOS, 143B, or MG-63 cells (p53 mutant). Cisplatin drastically increased the G2/M population in all cell lines. Combined tranilast and cisplatin further increased the proportion of cells in the G2/M phase from 34.8 to $59.1 \%$ in HOS cells $(\mathrm{P}=0.001)$, from 51.4 to $75.0 \%$ in $143 \mathrm{~B}$ cells $(\mathrm{P}=0.0001)$, from 67.7 to $85.1 \%$ in $\mathrm{U} 2 \mathrm{OS}$ cells $(\mathrm{P}=0.007)$, and from 24.2 to $41.3 \%$ in MG-63 cells $(\mathrm{P}=0.006)$ compared with cisplatin alone (Fig. 6). 

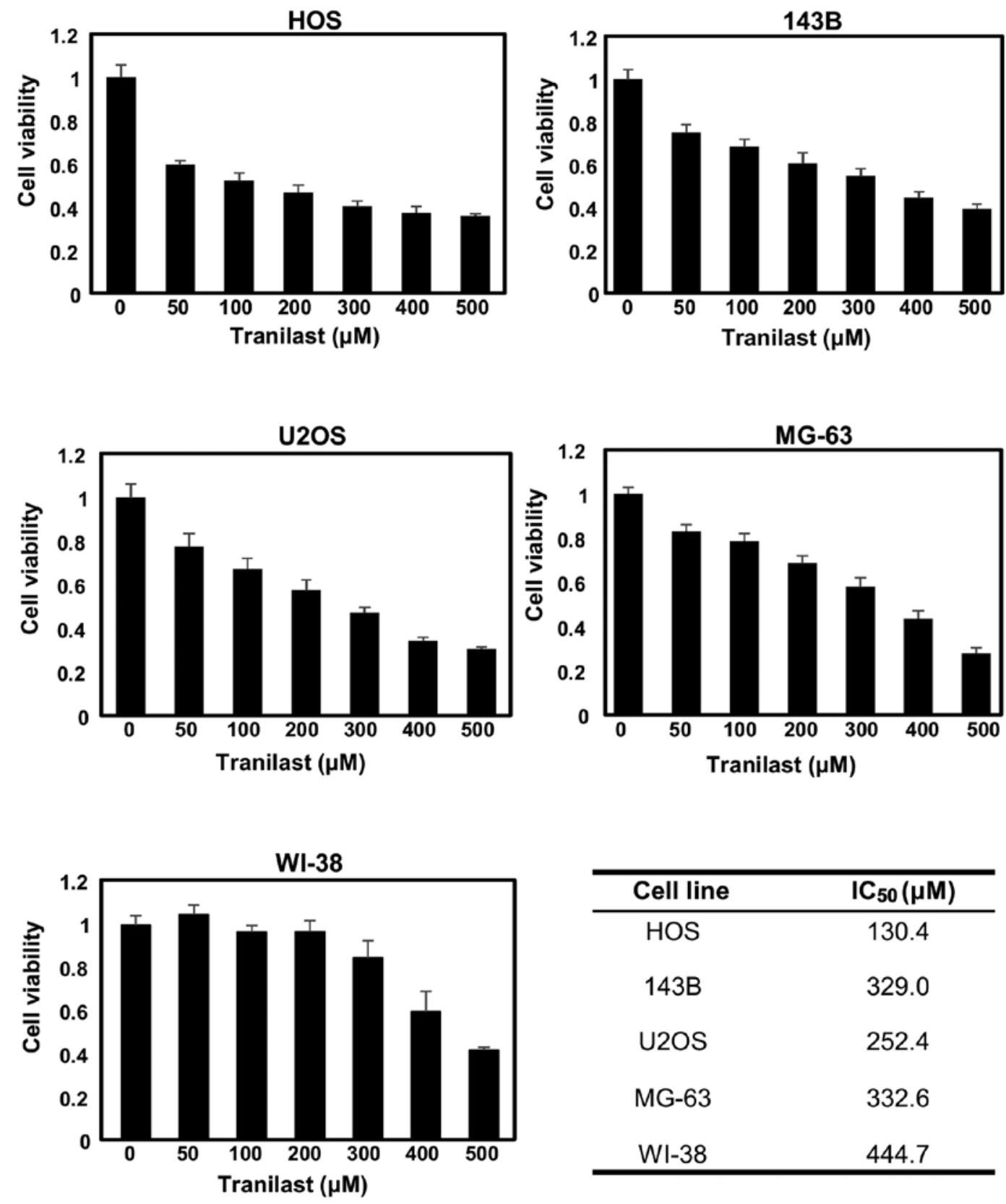

\begin{tabular}{cc}
\hline Cell line & IC $_{50}(\mu \mathrm{M})$ \\
\hline HOS & 130.4 \\
143B & 329.0 \\
U2OS & 252.4 \\
MG-63 & 332.6 \\
WI-38 & 444.7 \\
\hline
\end{tabular}

Figure 1. Inhibition of growth of osteosarcoma cell lines by tranilast. Osteosarcoma cell lines (HOS, 143B, U2OS and MG-63) and a normal fibroblast (WI-38) cell line were treated with tranilast and underwent cell viability assay $48 \mathrm{~h}$ after treatment. Tranilast inhibited proliferation of all cell lines in a dose-dependent manner; however, inhibition was significantly attenuated in WI-38 cells. Analysis of covariance (ANCOVA) of cell viability at 0-500 $\mu \mathrm{M}$ demonstrated significant statistical difference between four osteosarcoma cell lines and normal fibroblast WI-38 (vs. HOS, $\mathrm{P}=0.0007$; vs. 143B, P=0.0005; vs. U2OS, $\mathrm{P}=0.0001$; vs. MG-63, $\mathrm{P}=0.0003)$.

Tranilast and cisplatin enhance the ATR/CHK1 pathway in osteosarcoma cells. To explore the mechanism of enhancement of the G2/M phase after tranilast/cisplatin treatment, HOS, 143B and U2OS osteosarcoma cells were collected $48 \mathrm{~h}$ after treatment for western blotting with antibodies against cell-cycle regulators (Fig. 7). Tranilast enhanced expression of CHK1 and p-CDK1 (Y15), which is an inactivated form. Cisplatin enhanced expression of p-ATR, p-CHK1, p-CDK1 (Y15) and p-Weel (Fig. 7). Combined treatment increased p-CDK1 (Y15) more than cisplatin alone in all cell lines. These results suggest that $\mathrm{G} 2 / \mathrm{M}$ arrest was enhanced by increased expression of CHK1 under the cytotoxic ATR pathway and CDK1 inactivation was induced.
Tranilast enhances the effect of cisplatin on growth of osteosarcoma xenografts in mice. The osteosarcoma cell line 143B was implanted into the flank of nude mice to explore the effect of tranilast in combination with cisplatin. Tumor growth was significantly inhibited in the combination group compared with the control group $(\mathrm{P}=0.02)$, whereas cisplatin failed to reduce tumor volume significantly $(\mathrm{P}=0.11$; Fig. 8A and B). Cisplatin-treated mice showed significant loss of body weight at 4 weeks after initiation of the treatment (Fig. 8C). Combined treatment did not enhance this adverse effect, and the reduction in body weight was less than with cisplatin alone, although it was not statistically significant (Fig. 8C). 

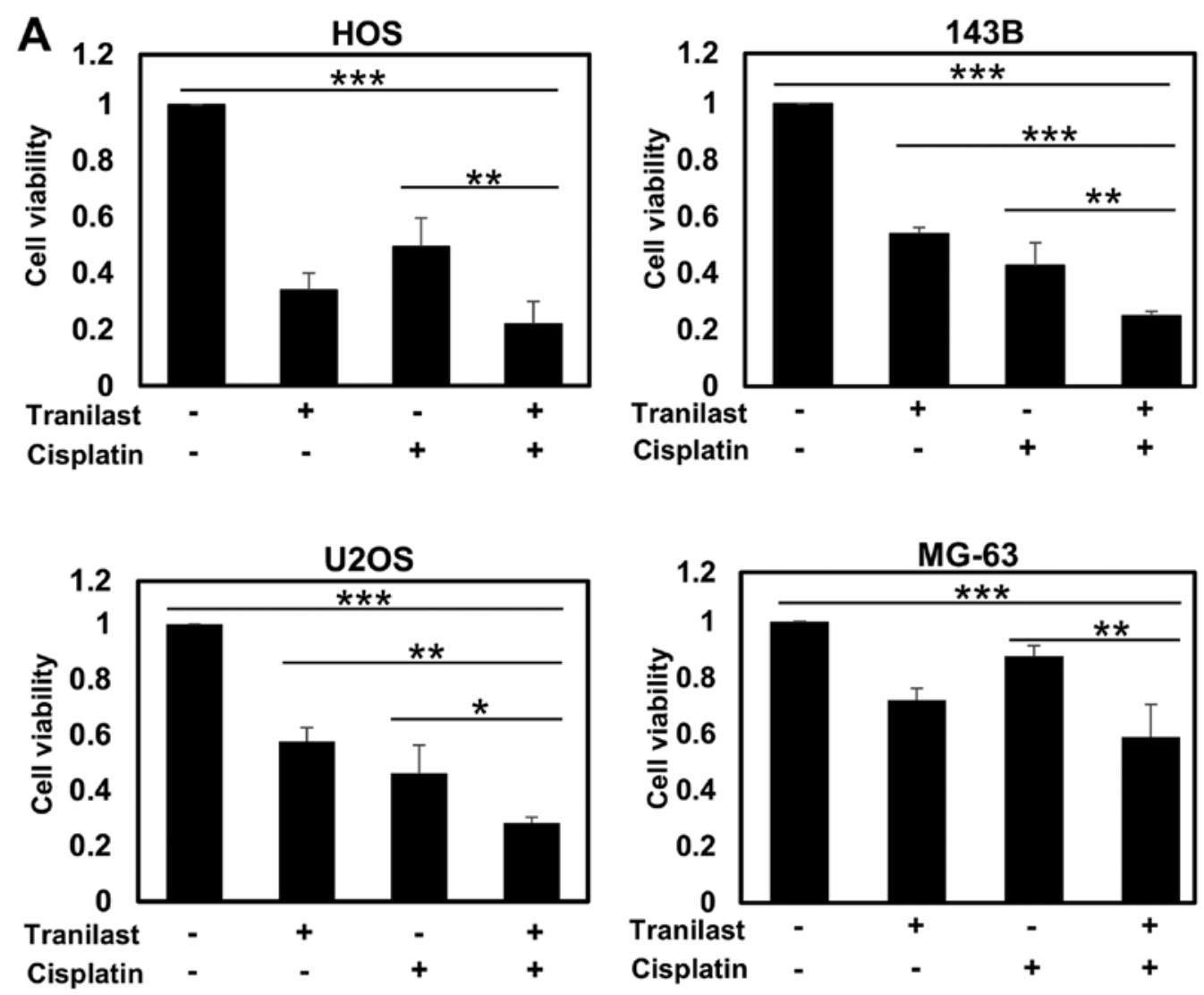

B
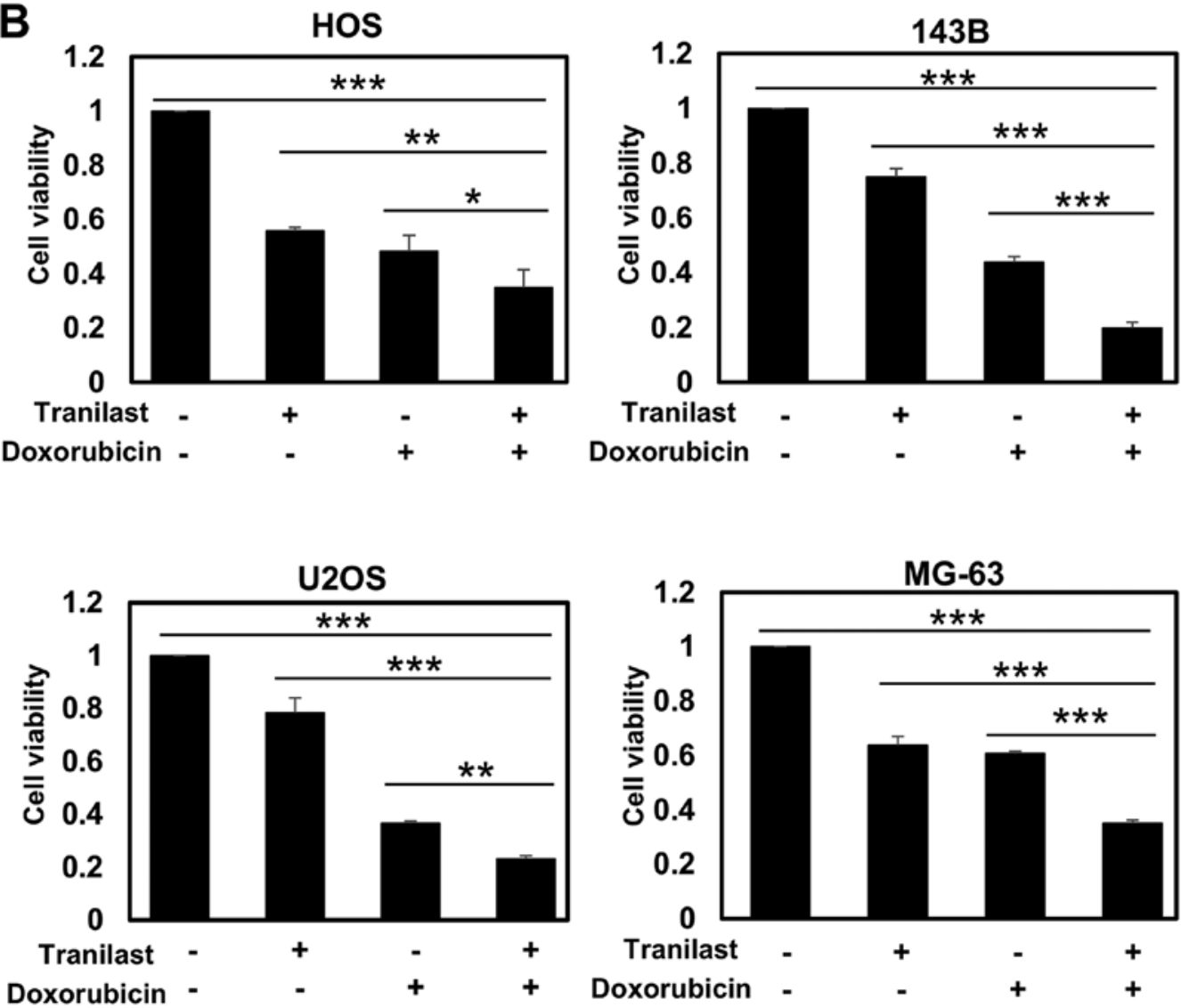

Figure 2. Enhancement of the cytotoxic effect of (A) cisplatin and (B) doxorubicin by tranilast in osteosarcoma cell lines. Human osteosarcoma cells (HOS, 143B, U2OS and MG-63) were treated with $200 \mu \mathrm{M}$ tranilast, anticancer drug ( $2 \mu \mathrm{M}$ cisplatin or $100 \mathrm{nM}$ doxorubicin) or $200 \mu \mathrm{M}$ tranilast combined with anticancer drug ( $2 \mu \mathrm{M}$ cisplatin or $100 \mathrm{nM}$ doxorubicin). Relative cell viability to the control group was analyzed in three independent experiments. Tranilast significantly enhanced the effect of cisplatin and doxorubicin in all cell lines tested $\left({ }^{*} \mathrm{P}<0.05,{ }^{* *} \mathrm{P}<0.01\right.$ and $\left.{ }^{* * * *} \mathrm{P}<0.001\right)$. 

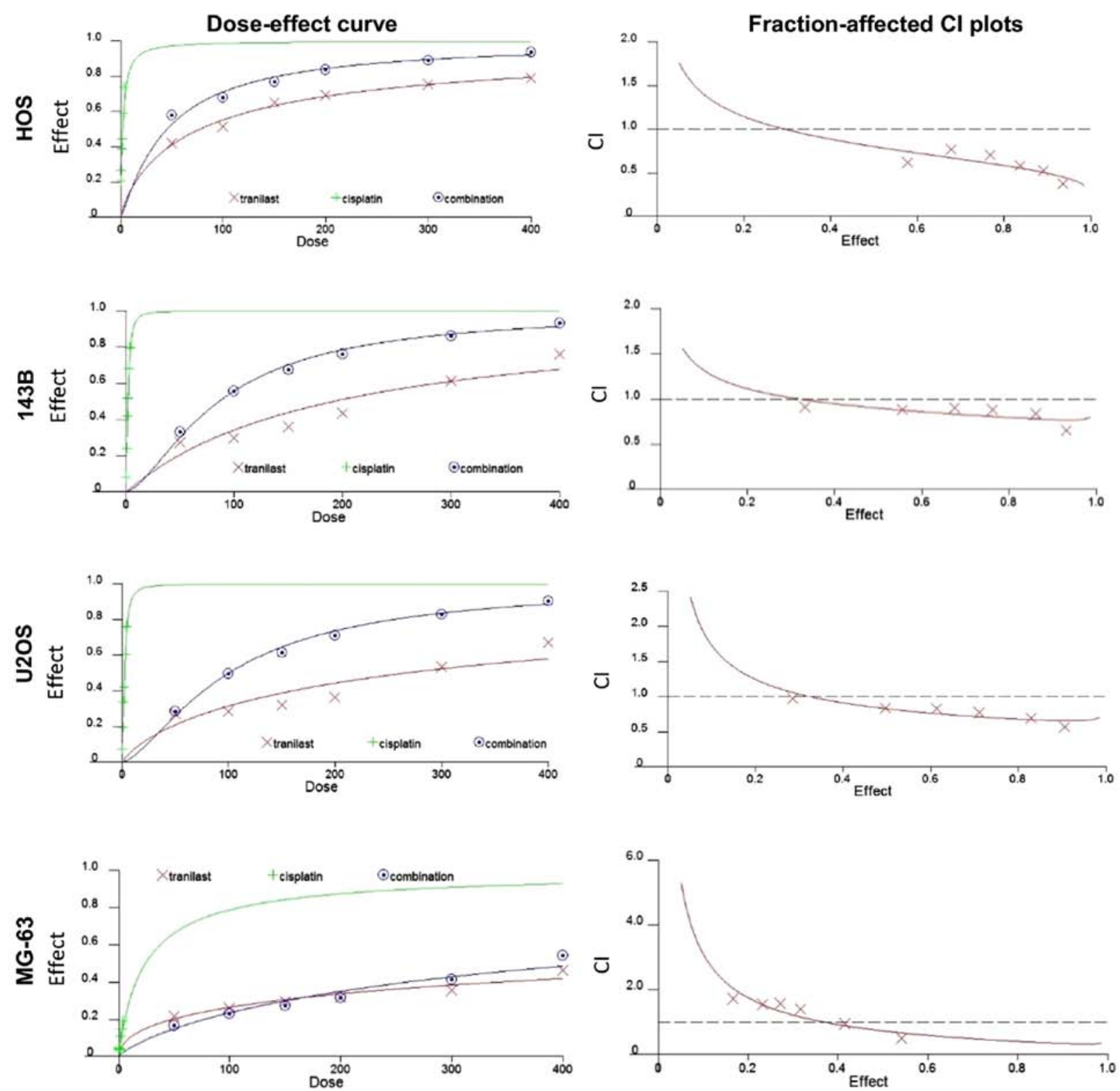

Figure 3. Synergistic cytotoxicity of tranilast and cisplatin in osteosarcoma cell lines. Dose-effect (left panels) and fraction-affected combination index (CI) plots (right panels) in osteosarcoma cell lines (HOS, 143B, U2OS and MG-63). Average CI values at effect levels $\mathrm{ED}_{50}, \mathrm{ED}_{75}$, and $\mathrm{ED}_{90}\left(\mathrm{ED}_{50}-\mathrm{ED}_{90} \mathrm{CI}\right)$ for tranilast in combination with cisplatin were 0.57 in HOS, 0.4 in 143B, 0.39 in U2OS and 0.51 in MG-63 cells, demonstrating synergistic cytotoxicity in osteosarcoma cell lines.

\section{Discussion}

Tranilast [N-(3',4'-dimethoxycinnamoyl)-anthranilic acid] was originally thought to exert its antiallergic effect via inhibition of chemical mediator release from mast cells (20). Additional effects of inhibition of keloids and hypertrophic scar are mediated by inhibited production of collagen by skin fibroblasts (21). It is also suggested that tranilast inhibits the release of transforming growth factor (TGF)- $\beta 1$ from fibroblasts (21). The mechanism of the anticancer effect of tranilast has not been completely clarified. Subramaniam et al showed that tranilast induced G1/S arrest and reduced migration in a murine breast cancer cell line, which seemed to be mediated through TGF- $\beta$ modulation (22).

Cisplatin mainly induces apoptosis in osteosarcoma cells via $\mathrm{G} 2 / \mathrm{M}$ arrest; thus, we explored cell-cycle regulators after treatment. DNA-damaging treatment, including cisplatin, activates cell-cycle checkpoints, which induce G1/S arrest followed by $\mathrm{G} 2 / \mathrm{M}$ arrest (23). Cancer cells defective in the p53 pathway lack the G1 checkpoint and depend on the G2/M checkpoint. Our results showed that cisplatin induced G2/M arrest in all four osteosarcoma cell lines, although U2OS cells harbored wild-type p53. This could be explained by previous evidence that cisplatin does not frequently induce significant G1 phase accumulation, largely because cells remain trapped in the G2/M phase (24). Cisplatin is known to induce ATR kinase (24), thereby activating downstream CHK1.

In the present study, this pathway was activated to induce G2/M arrest, regardless of p53 status in osteosarcoma cells. This suggests that in osteosarcoma cells, at least in part, ATR/CHK1 may work independently of p53 function. Regarding induction of the cyclin-dependent kinase inhibitor p21 after treatment, p53-expressing U2OS cells showed higher p21 levels after cisplatin and/or tranilast 


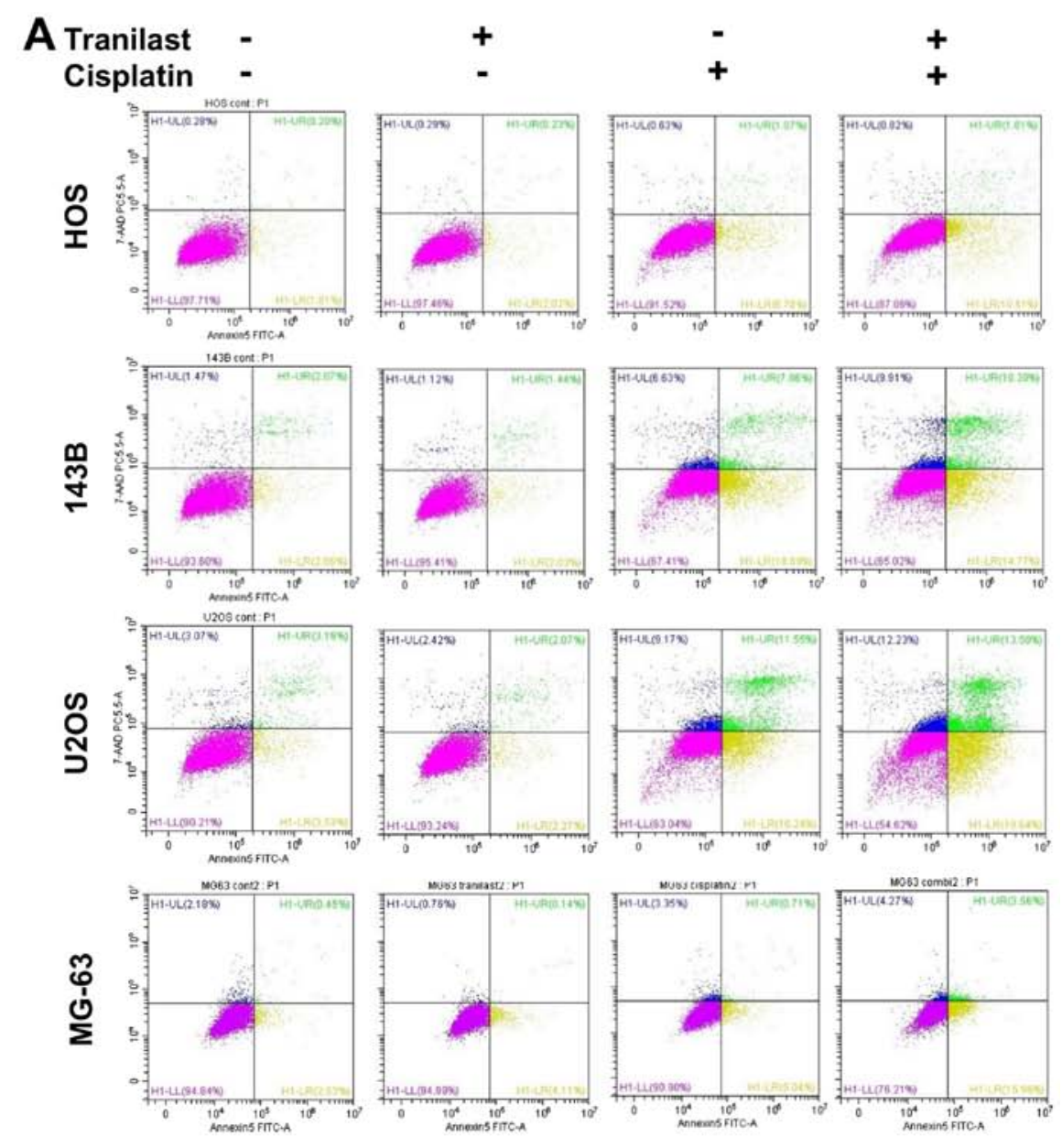

B

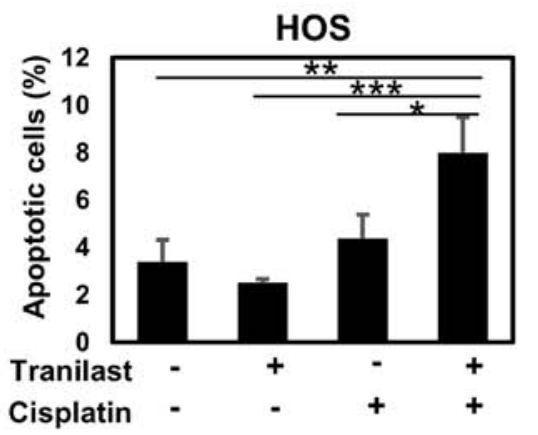

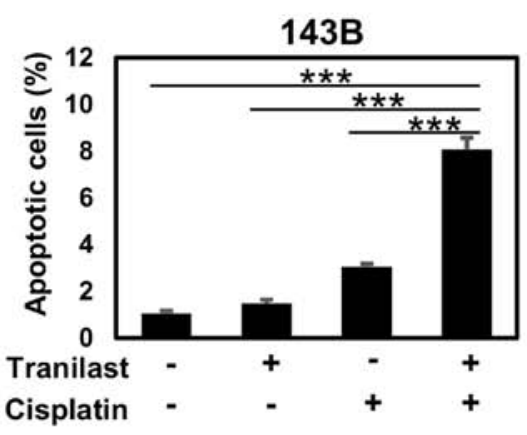
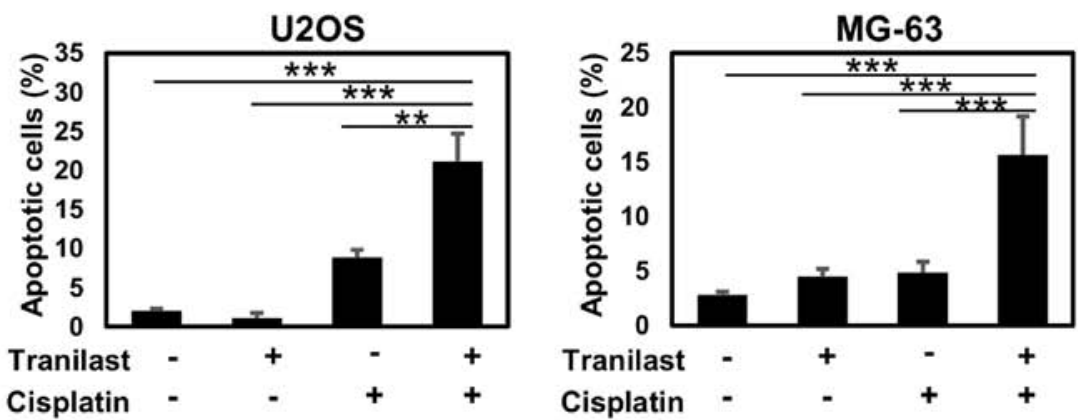

Figure 4. Enhancement by tranilast of cisplatin-induced apoptosis in osteosarcoma cell lines. (A) After treatment of osteosarcoma cells (HOS, 143B, U2OS and MG-63) with tranilast, cisplatin and their combination, flow cytometry was used to analyze the mode of cell death. Tranilast alone did not induce significant apoptotic cell death in all cell lines. Cisplatin induced apparent accumulation of cells in early and late apoptosis. Combination treatment with tranilast and cisplatin enhanced both early and late apoptotic cell death. (B) Quantitative analysis ( $n=3$, mean \pm SD) demonstrated statistically significant induction of apoptosis (early and late apoptosis) in all cell lines compared with other treatment groups $\left({ }^{*} \mathrm{P}<0.05,{ }^{* * *} \mathrm{P}<0.01\right.$ and $\left.{ }^{* * * *} \mathrm{P}<0.001\right)$. 

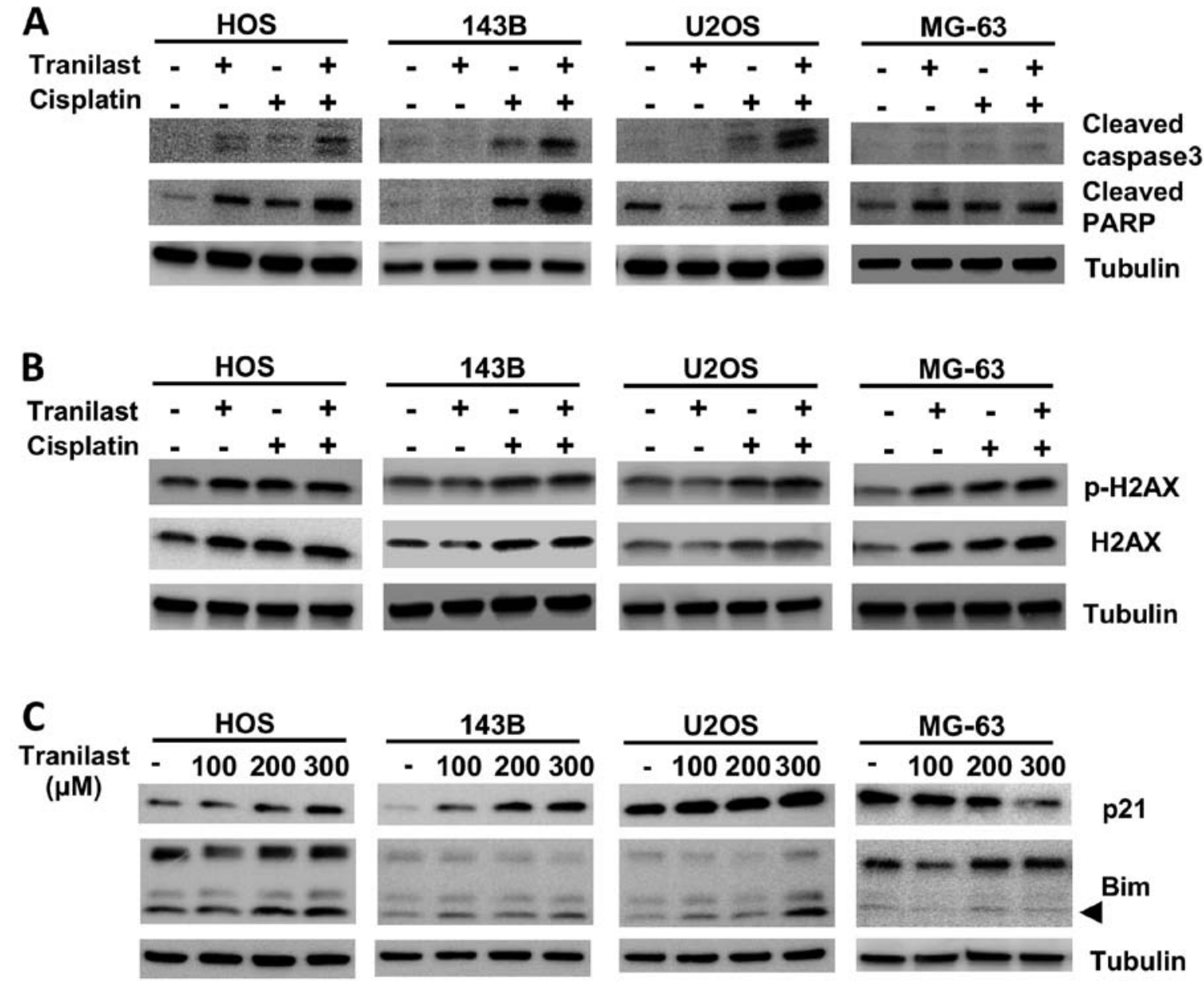

Figure 5. Expression of proteins related to apoptosis and the cell cycle after treatment of osteosarcoma cell lines with tranilast or cisplatin. Cisplatin increased expression of (A) cleaved poly(ADP-ribose) polymerase, cleaved caspase-3 and (B) phospho-H2A histone family member X (p-H2AX). Expression was further enhanced by tranilast in combination with cisplatin. (C) Expression of p21 was increased in a dose-dependent manner by tranilast. Expression of proapoptotic Bim protein was also increased by tranilast treatment (arrowhead, active form of Bim).

treatment than those observed in HOS and 143B, p53 mutant cells. Therefore, in p53-expressing osteosarcoma cells, p21 and p53 cooperatively work to induce apoptosis via several factors including pro-apoptotic protein Bim. Nevertheless, our results demonstrated that tranilast could enhance sensitivity to cisplatin, irrespective of the status of the p53 pathway (Fig. 9), which is frequently impaired in osteosarcoma patients (25).

Advancement of multiagent chemotherapy regimens for osteosarcoma has led to a dramatic improvement in the prognosis for patients with localized disease. The first chemotherapeutic agents were doxorubicin and high-dose methotrexate with leucovorin in the 1970s. Other drugs such as cisplatin, ifosfamide and cyclophosphamide have proven efficacy in the treatment of osteosarcoma; however, they do not completely eradicate metastatic lesions (26). Although a combination of cytotoxic agents produces enhanced anticancer efficacy, adverse effects sometimes compromise the condition of the patient and treatment may need to be terminated. Non-cytotoxic agents that potentiate cancer cells to chemotherapeutic drugs have been discovered. Caffeine has been shown to enhance the effect of anticancer drugs by inhibiting DNA repair and cell-cycle checkpoints (27). The natural antioxidant resveratrol is reported to overcome multidrug resistance by modulating $\mathrm{ABC}$ transporter proteins (28).
Tranilast, which has been used in many patients since the 1980s, has demonstrated its activity as an enhancer or sensitizer of several anticancer drugs in different types of cancer (29). Murahashi et al have shown that the combined treatment of cisplatin and tranilast decreased fibrosis and mitosis and increased apoptosis in scirrhous gastric cancer cells (30). Tranilast also sensitizes pancreatic cancer cells to gemcitabine through suppression of DNA synthesis enzymes (31). In breast cancer, tranilast has been shown to synergistically act with tamoxifen, which was mediated by vascular endothelial growth factor and matrix metalloproteinase-9 (32). In the present study, we first showed that tranilast alone inhibited proliferation in osteosarcoma cell lines and synergistically acted in combination with cisplatin.

It was reported that serum concentrations of tranilast reach 30-300 $\mu \mathrm{M}$ in vivo after oral administration of $600 \mathrm{mg} /$ day tranilast (33). Since the $\mathrm{IC}_{50}$ values of tranilast in osteosarcoma cells were 130-330 $\mu \mathrm{M}$ (Fig. 1), tranilast monotherapy may not be sufficient to exert strong antitumor effects in vivo. However, the concentration of tranilast when used in combination with cisplatin was $200 \mu \mathrm{M}$, which can be achieved by the oral administration of tranilast at the currently approved dose (600 mg/day). In addition, since normal fibroblasts were not significantly damaged at $200 \mu \mathrm{M}$ of tranilast (Fig. 1), tranilast can be used safely in patients. 

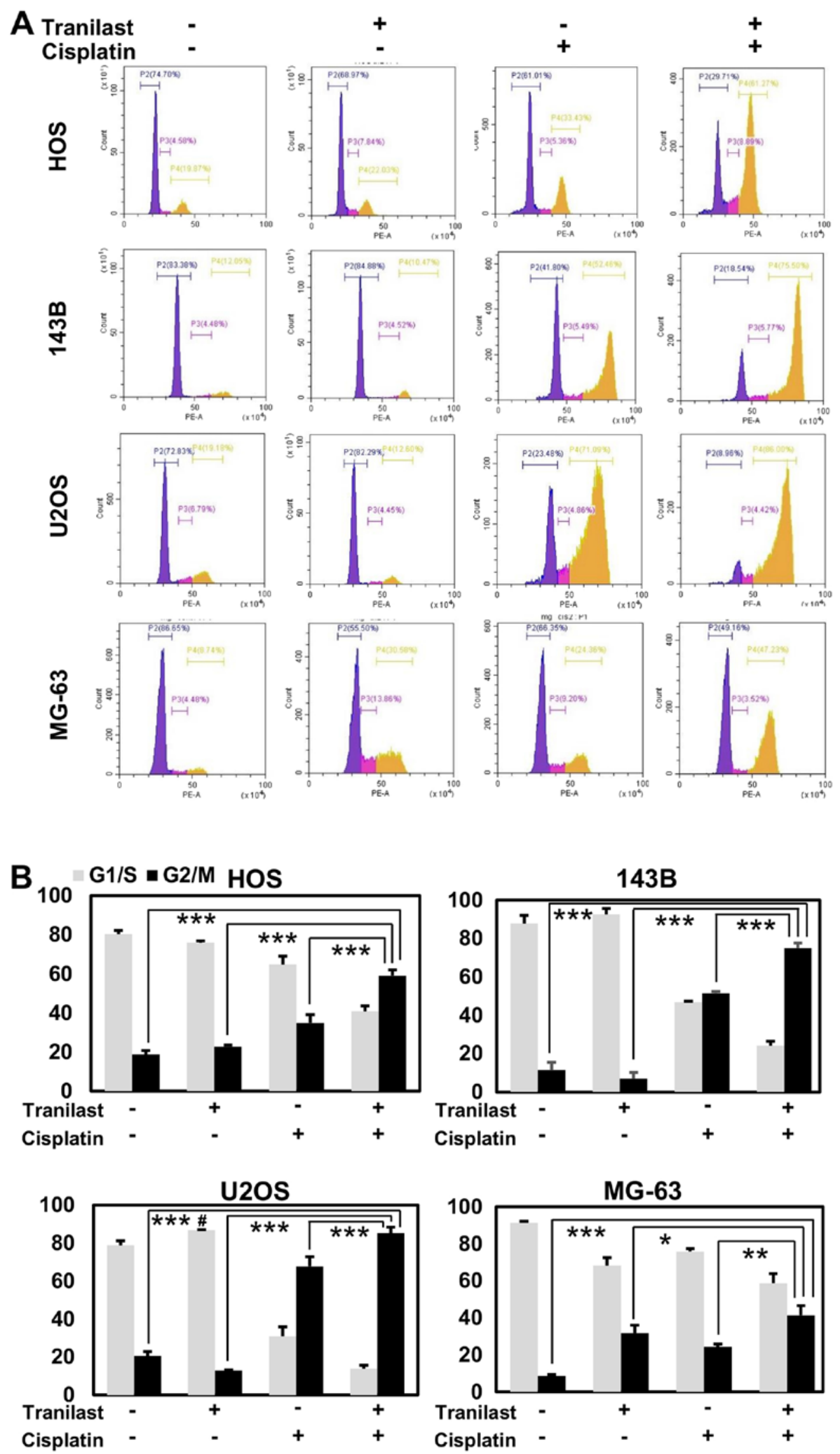

Figure 6. Cell cycle analysis using flow cytometry after tranilast and/or cisplatin treatment. (A) Tranilast induced a small increase in the G1 phase population of U2OS cells (p53 wild-type) but not of HOS, 143B or MG-63 cells (p53 mutant). Cisplatin treatment markedly increased the G2/M population in all cell lines. Combined treatment with tranilast and cisplatin further increased G2/M accumulation in osteosarcoma cell lines compared with cisplatin alone. (B) Quantitative analysis $\left(\mathrm{n}=3\right.$, mean $\pm \mathrm{SD}$ ) demonstrated statistically significant increase in G1/S population only in U2OS cells $\left({ }^{*} \mathrm{P}=0.04\right)$. Treatment with tranilast and cisplatin significantly increased G2/S population compared with other treatment group in all four cell lines $\left({ }^{*} \mathrm{P}<0.05,{ }^{* * *} \mathrm{P}<0.01\right.$ and $\left.{ }^{* * * *} \mathrm{P}<0.001\right)$. 
A

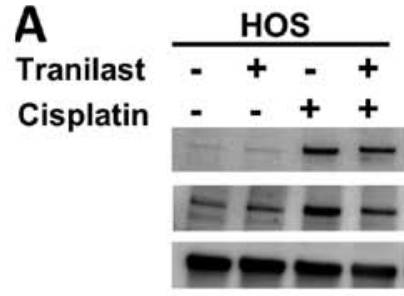

B

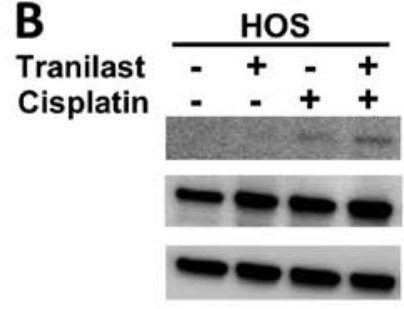

C

Tranilast Cisplatin
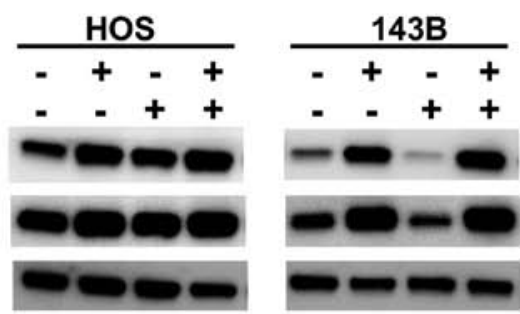

D

Tranilast
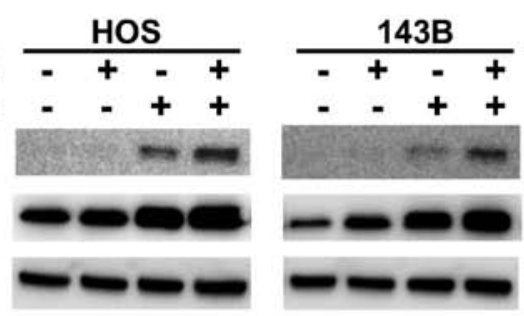

E
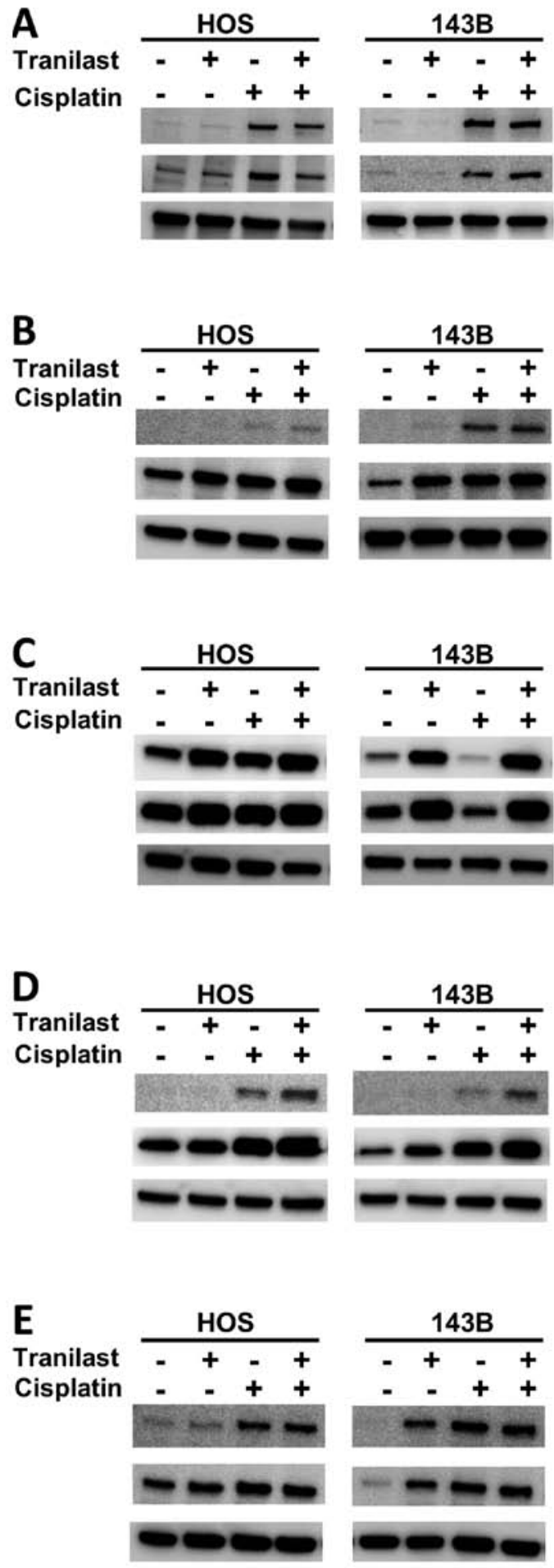
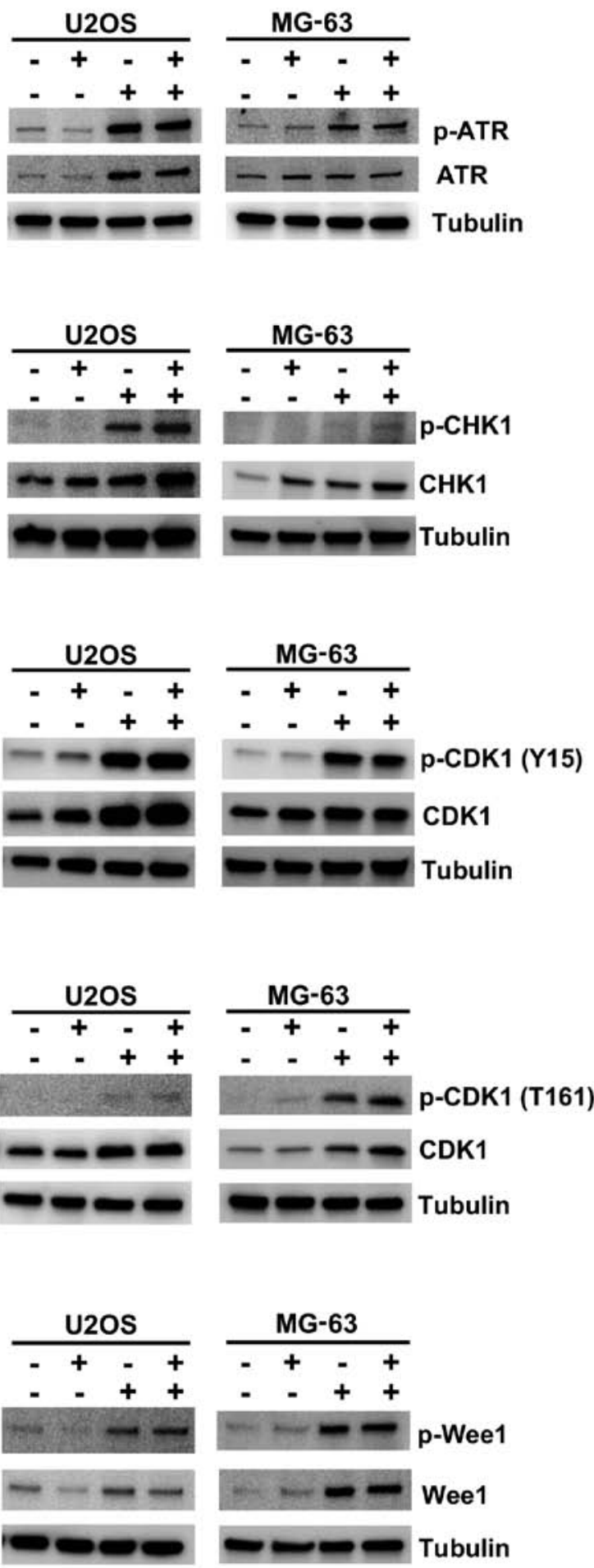

Figure 7. Analysis of protein expression levels of cell-cycle regulators to explore the mechanism of enhancement of the G2/M phase after tranilast/cisplatin treatment in osteosarcoma cells. (A-C and E) Cisplatin induced enhanced expression of phospho-ataxia telangiectasia and Rad3-related kinase (p-ATR), p-CHK1, p-CDK1 (Y15) and p-Wee1. Tranilast alone induced enhanced expression of the checkpoint inhibitor (CHK)1 (B) and phospho-cyclin-dependent kinase (p-CDK)1 at Y15 (inactivated form). (C) Combined treatment showed increased expression of p-CDK1 (Y15) compared with cisplatin treatment alone in all cell lines, except MG-63 cells. (D) Cisplatin weakly induced p-CDK1 at T161 (active form).

High-dose cisplatin therapy for osteosarcoma patients may cause severe toxicity including permanent hearing loss and kidney damage. The prevalence of hearing loss in children treated with platinum analogs ranges from 2 to $90 \%$. Recently, a clinical trial with pantoprazole, an inhibitor of the organic cation transporter 2, has been performed; however, it did not ameliorate ototoxicity and nephrotoxicity induced by cisplatin (34). If tranilast sufficiently improves the therapeutic outcome of osteosarcoma patients, decreasing the dose of cisplatin or other agents may reduce the risk of severe adverse effects caused by anticancer drugs.

In conclusion, tranilast was originally established as an antiallergic agent. It has a cytostatic effect in osteosarcoma cells and enhances the effect of anticancer drugs, especially cisplatin 


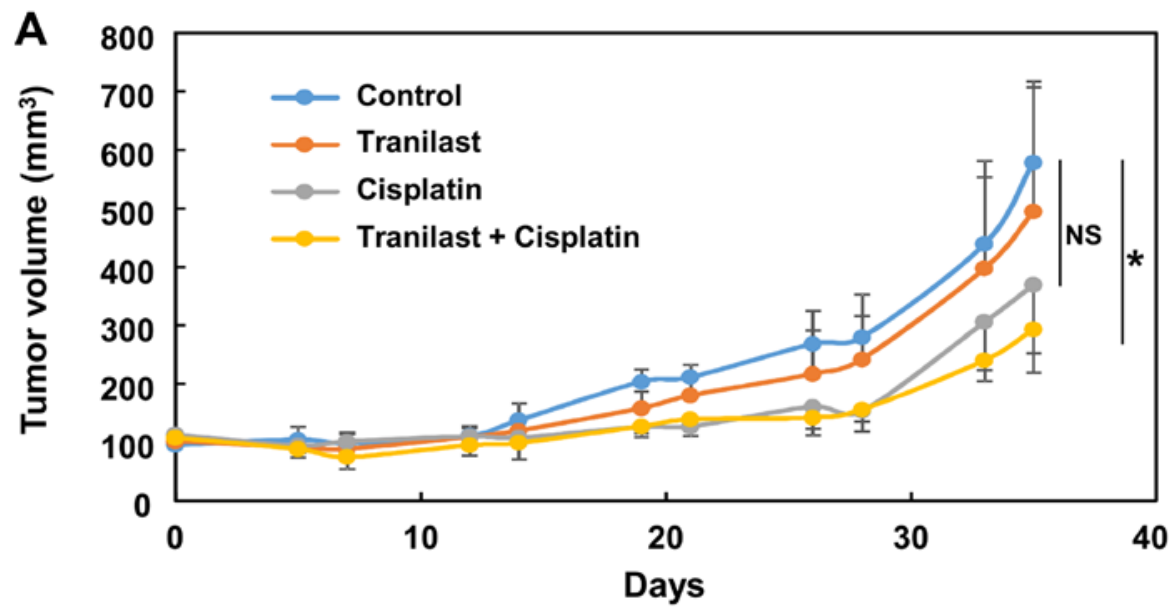

B
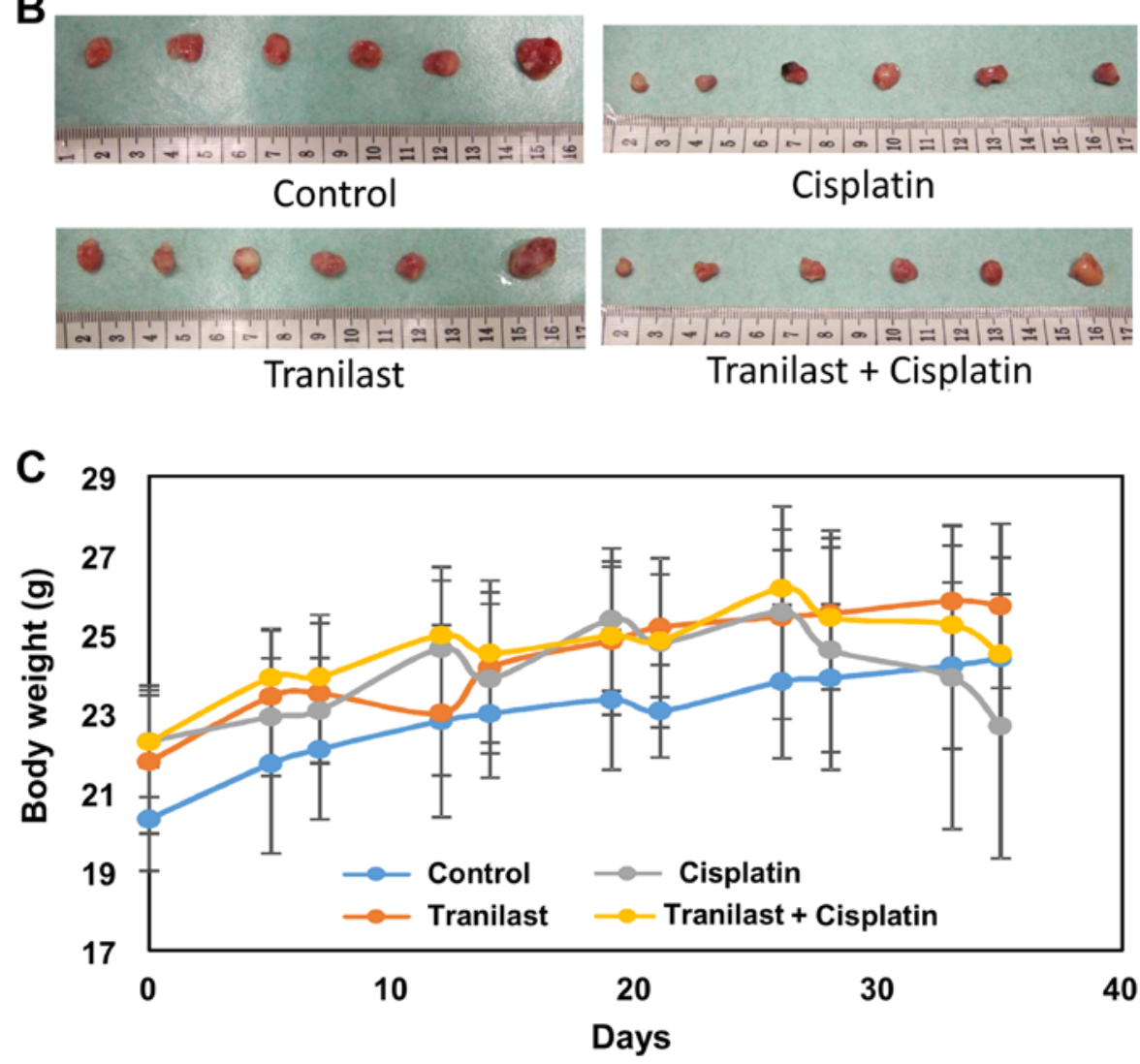

Figure 8. Animal study with 143B xenografts in nude mice was utilized to explore the effect of tranilast in combination with cisplatin. (A) Tumor growth was significantly inhibited in the tranilast and cisplatin combination group compared with the control group ( $(\mathrm{P}=0.02)$, whereas the cisplatin group failed to induce a significant reduction in tumor volume (NS, not significant; $\mathrm{P}=0.11$ ). (B) Gross appearance of the xenografts at the time of sacrifice in the control and treatment groups. (C) Cisplatin-treated mice showed significant loss of body weight 4 weeks after initiation of treatment. Combined treatment with cisplatin and tranilast did not exacerbate the reduction in body weight.

in vitro and in vivo. The enhanced sensitivity to cisplatin is mediated by enhanced apoptosis induced by G2/M arrest. Tranilast has been clinically approved and has few adverse effects; therefore, clinical trials that evaluate tranilast in combination with chemotherapy in osteosarcoma should be undertaken.

\section{Acknowledgements}

We are grateful to Hui Gao (Technical assistant at the Department of Orthopaedic Surgery, Graduate School of
Medical and Dental Sciences, Kagoshima University) for her excellent technical assistance. We wish to thank the Joint Research Laboratory of Kagoshima University Graduate School of Medical and Dental Sciences.

\section{Funding}

The present study was supported by Grants-in-Aid for Scientific Research (KAKENHI) (C) 15K10452 and (C) 17K10973. 

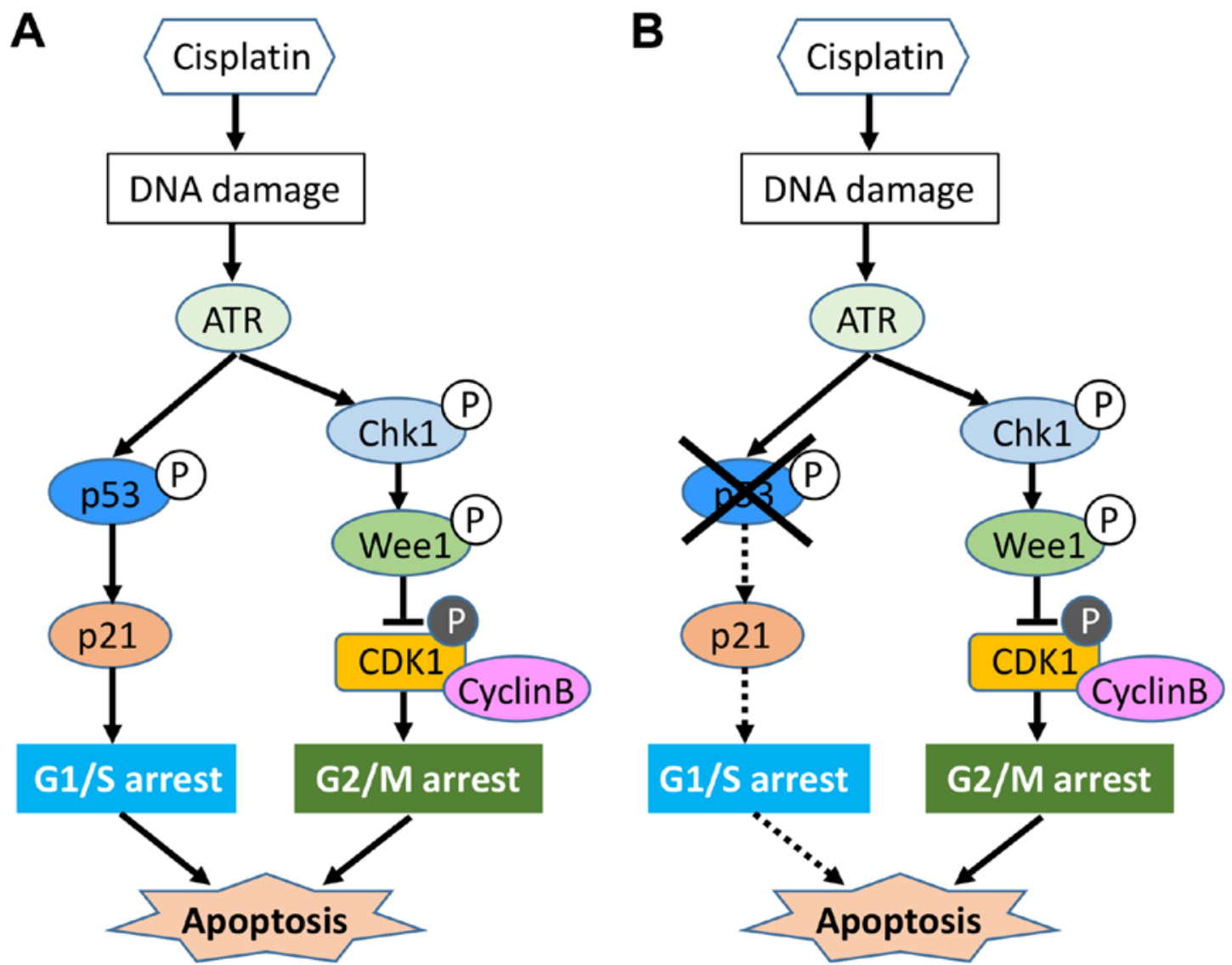

Figure 9. Cisplatin-induced apoptosis in p53-intact and p53-disrupted signaling pathway conditions. (A) In the cell lines with an intact p53 pathway, cisplatin-induced DNA damage activated ataxia telangiectasia and Rad3-related kinase (ATR). ATR induced phosphorylation (P) of p53, which activated cyclin-dependent kinase (CDK) inhibitor p21, resulting in cell cycle arrest. Cell cycle checkpoint protein, Chk1 and Wee1 were sequentially activated to inactivate CDK1, resulting in G2/M arrest. (B) In the condition of a disrupted p53 pathway, since G1/S arrest was not induced, G2/M arrest was the main mechanism for cell growth arrest and apoptosis.

\section{Availability of data and materials}

The datasets used and/or analyzed during the current study are available from the corresponding author on reasonable request.

\section{Authors' contributions}

TN, SN, HS, SM, SK and NT were involved in the conception and design of the study; TN and YS performed the experiments; SM and HS were involved in planning and supervised the experiments of western blotting and cell viability assays; TS and SK were involved in planning and supervision of the animal experiments: TN, HS, YS and SN analyzed the data; SN, TS and SM performed the interpretation of the results and drafted the manuscript; SK and NT provided critical revisions of the manuscript. All authors read and approved the manuscript and agree to be accountable for all aspects of the research in ensuring that the accuracy or integrity of any part of the work are appropriately investigated and resolved.

\section{Ethics approval and consent to participate}

The animal experiment was approved by the Association for the Accreditation and Assessment of Laboratory Animal Care
(Kagoshima, Japan). All animal experiments were performed in compliance with the guidelines of the Institute of Laboratory Animal Sciences, Graduate School of Medical and Dental Sciences, Kagoshima University.

\section{Patient consent for publication}

Not applicable.

\section{Competing interests}

The authors declare that they have no competing interests.

\section{References}

1. Darakhshan S and Pour AB: Tranilast: A review of its therapeutic applications. Pharmacol Res 91: 15-28, 2015.

2. Ward MR, Sasahara T, Agrotis A, Dilley RJ, Jennings GL and Bobik A: Inhibitory effects of tranilast on expression of transforming growth factor-beta isoforms and receptors in injured arteries. Atherosclerosis 137: 267-275, 1998.

3. Phan TV, Ke K, Sul OJ, Park YK, Kim KK, Cho YS, Chung HT and Choi HS: Protection against ovariectomy-induced bone loss by tranilast. PLoS One 9: e95585, 2014.

4. Holmes DR Jr, Savage M, LaBlanche JM, Grip L, Serruys PW, Fitzgerald P, Fischman D, Goldberg S, Brinker JA, Zeiher AM, et al: Results of prevention of REStenosis with tranilast and its outcomes (PRESTO) trial. Circulation 106: 1243-1250, 2002. 
5. Huang Y, Jiang H, Chen Y, Wang X, Yang Y, Tao J, Deng X, Liang G, Zhang H, Jiang W and Zhou R: Tranilast directly targets NLRP3 to treat inflammasome-driven diseases. EMBO Mol Med 10: e8689, 2018.

6. Tokuyama H, Kelly DJ, Cox A, Zhang Y, Thai K, NikolicPaterson DJ and Gilbert RE: Tranilast ameliorates experimental mesangial proliferative glomerulonephritis. Nephron Exp Nephrol 109: e1-e7, 2008.

7. Darakhshan S, Bidmeshkipour A, Mansouri K, Saeid HM and Ghanbari A: The effects of tamoxifen in combination with tranilast on CXCL12-CXCR4 axis and invasion in breast cancer cell lines. Iran J Pharm Res 13: 683-693, 2014.

8. Subramaniam V, Ace O, Prud'homme GJ and Jothy S: Tranilast treatment decreases cell growth, migration and inhibits colony formation of human breast cancer cells. Exp Mol Pathol 90: 116-122, 2011

9. Izumi K, Mizokami A, Li YQ, Narimoto K, Sugimoto K, Kadono Y, Kitagawa Y, Konaka H, Koh E, Keller ET and Namiki M: Tranilast inhibits hormone refractory prostate cancer cell proliferation and suppresses transforming growth factor beta1-associated osteoblastic changes. Prostate 69: 1222-1234, 2009.

10. Kaneda M, Obara H, Suzuki K, Takeuchi O, Takizawa A, Osaku M, Matsubara H and Kitagawa Y: Evaluation of suppressive effects of tranilast on the invasion/metastasis mechanism in a murine pancreatic cancer cell line. Pancreas 46: 567-574, 2017.

11. Yatsunami J, Aoki S, Fukuno Y, Kikuchi Y, Kawashima M and Hayashi SI: Antiangiogenic and antitumor effects of tranilast on mouse lung carcinoma cells. Int J Oncol 17: 1151-1156, 2000.

12. Yashiro M, Murahashi K, Matsuoka T, Nakazawa K, Tanaka H, Osaka H, Koyama T, Ohira $\mathbf{M}$ and Chung KH: Tranilast (N-3,4-dimethoxycinamoyl anthranilic acid): A novel inhibitor of invasion-stimulating interaction between gastric cancer cells and orthotopic fibroblasts. Anticancer Res 23: 3899-3904, 2003.

13. Meazza C and Scanagatta P: Metastatic osteosarcoma: A challenging multidisciplinary treatment. Expert Rev Anticancer Ther 16: 543-556, 2016.

14. Chandar N, Billig B, McMaster J and Novak J: Inactivation of p53 gene in human and murine osteosarcoma cells. Br J Cancer 65: 208-214, 1992

15. GanjaviH, GeeM,Narendran A,Parkinson N,Krishnamoorthy M, Freedman MH and Malkin D: Adenovirus-mediated p53 gene therapy in osteosarcoma cell lines: Sensitization to cisplatin and doxorubicin. Cancer Gene Ther 13: 415-419, 2006.

16. Allan LA and Fried M: p53-dependent apoptosis or growth arrest induced by different forms of radiation in U2OS cells: p21WAF1/CIP1 repression in UV induced apoptosis Oncogene 18: 5403-5412, 1999.

17. Nakamura S, Nagano S, Nagao H, Ishidou Y, Yokouchi M, Abematsu M, Yamamoto T, Komiya S and Setoguchi T: Arsenic trioxide prevents osteosarcoma growth by inhibition of GLI transcription via DNA damage accumulation. PLoS One 8: e69466, 2013.

18. Takahashi K, Setoguchi T, Tsuru A, Saitoh Y, Nagano S, Ishidou Y, Maeda S, Furukawa T and Komiya S: Inhibition of casein kinase 2 prevents growth of human osteosarcoma. Oncol Rep 37: 1141-1147, 2017.

19. Chou TC and Talalay P: Quantitative analysis of dose-effect relationships: The combined effects of multiple drugs or enzyme inhibitors. Adv Enzyme Regul 22: 27-55, 1984.
20. Isaji M, Miyata $\mathrm{H}$, Ajisawa $\mathrm{Y}$, Takehana $\mathrm{Y}$ and Yoshimura $\mathrm{N}$ : Tranilast inhibits the proliferation, chemotaxis and tube formation of human microvascular endothelial cells in vitro and angiogenesis in vivo. Br J Pharmacol 122: 1061-1066, 1997.

21. Suzawa H, Kikuchi S, Arai N and Koda A: The mechanism involved in the inhibitory action of tranilast on collagen biosynthesis of keloid fibroblasts. Jpn J Pharmacol 60: 91-96, 1992.

22. Subramaniam V, Chakrabarti R, Prud'homme GJ and Jothy S: Tranilast inhibits cell proliferation and migration and promotes apoptosis in murine breast cancer. Anticancer Drugs 21: 351-361, 2010.

23. Shapiro GI and Harper JW: Anticancer drug targets: Cell cycle and checkpoint control. J Clin Invest 104: 1645-1653, 1999.

24. Siddik ZH: Cisplatin: Mode of cytotoxic action and molecular basis of resistance. Oncogene 22: 7265-7279, 2003.

25. Goto A, Kanda H, Ishikawa Y, Matsumoto S, Kawaguchi N, Machinami R, Kato Y and Kitagawa T: Association of loss of heterozygosity at the $\mathrm{p} 53$ locus with chemoresistance in osteosarcomas. Jpn J Cancer Res 89: 539-547, 1998.

26. Jaffe N: Historical perspective on the introduction and use of chemotherapy for the treatment of osteosarcoma. Adv Exp Med Biol 804: 1-30, 2014.

27. Sabisz M and Skladanowski A: Modulation of cellular response to anticancer treatment by caffeine: Inhibition of cell cycle checkpoints, DNA repair and more. Curr Pharm Biotechnol 9: 325-336, 2008.

28. Hu Y, Li C, Li H, Li M and Shu X: Resveratrol-mediated reversal of tumor multi-drug resistance. Curr Drug Metab 15: 703-710, 2014.

29. Rogosnitzky M, Danks R and Kardash E: Therapeutic potential of tranilast, an anti-allergy drug, in proliferative disorders. Anticancer Res 32: 2471-2478, 2012.

30. Murahashi K, Yashiro M, Inoue T, Nishimura S, Matsuoka T, Sawada T, Sowa M and Hirakawa-Ys Chung K: Tranilast and cisplatin as an experimental combination therapy for scirrhous gastric cancer. Int J Oncol 13: 1235-1240, 1998.

31. Mitsuno M, Kitajima Y, Ohtaka K, Kai K, Hashiguchi K, Nakamura J, Hiraki M, Noshiro H and Miyazaki K: Tranilast strongly sensitizes pancreatic cancer cells to gemcitabine via decreasing protein expression of ribonucleotide reductase 1 . Int $J$ Oncol 36: 341-349, 2010.

32. Darakhshan S, Bidmeshkipour A, Khazaei M, Rabzia A and Ghanbari A: Synergistic effects of tamoxifen and tranilast on VEGF and MMP-9 regulation in cultured human breast cancer cells. Asian Pac J Cancer Prev 14: 6869-6874, 2013.

33. Kusama H, Kikuchi S, Tazawa S, Katsuno K, Baba Y, Zhai YL, Nikaido T and Fujii S: Tranilast inhibits the proliferation of human coronary smooth muscle cell through the activation of p21waf1. Atherosclerosis 143: 307-313, 1999.

34. Fox E, Levin K, Zhu Y, Segers B, Balamuth N, Womer R, Bagatell R and Balis F: Pantoprazole, an inhibitor of the organic cation transporter 2, does not ameliorate cisplatin-related ototoxicity or nephrotoxicity in children and adolescents with newly diagnosed osteosarcoma treated with methotrexate, doxorubicin, and cisplatin. Oncologist 23: 762-e779, 2018.

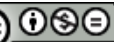

This work is licensed under a Creative Commons Attribution-NonCommercial-NoDerivatives 4.0 International (CC BY-NC-ND 4.0) License. 